Original title / titulo original: Acerca de la insólita carrera de la bandera wiphala

Author(s)/ autor(es): Magdalena Śniadecka-Kotarska

Published originally as/ Publicado originalmente en:

Estudios Latinoamericanos, 30 (2010), pp. 7-24

DOI:https://doi.org/10.36447/Estudios2010.v30.art1

Estudios Latinoamericanos is a journal published by the Polish Society for Latin American Studies (Polskie Towarzystwo Studiów Latynoamerykanistycznych).

The Polish Society for Latin American Studies is scholarly organization established to facilitate research on Latin America and to encourage and promote scientific and cultural cooperation between Poland and Latin America.

Estudios Latinoamericanos, revista publicada por la Sociedad Polaca de Estudios Latinoamericanos (Polskie Towarzystwo Studiów Latynoamerykanistycznych).

Sociedad Polaca de Estudios Latinoamericanos es una asociación científica fundada con el fin de desarrollar investigaciones científicas sobre América Latina y participar en la cooperación científica y cultural entre las sociedades de Polonia y América Latina. 


\title{
Acerca de la insólita carrera de la bandera wiphala
}

\author{
Magdalena Śniadecka-Kotarska
}

$\mathrm{E}^{1}$ n los países andinos, el difícil desarrollo de los movimientos indígenas, destinados a potenciar sus señas de identidad, vino acompañado, en la década de los 1990, de la retórica y el simbolismo étnicos antes insignificantes o incluso ausentes. Uno de los elementos más característicos del fenómeno fue la aparición de la bandera con los colores del arco iris, llamada wiphala. En un periodo de tiempo relativamente breve, se convirtió en un símbolo omnipresente en todas las protestas indígenas, no sólo de la región andina de Ecuador o Bolivia, sino de todo el continente americano. Este elemento multicolor, esta bandera, es un signo fácilmente discernible durante las marchas masivas, las huelgas y toda clase de protestas, una suerte de transmisor de información para los manifestantes, pues subraya, en primer lugar, su diferencia étnica y, después, la voluntad de creación de una unidad panétnica. A la luz de los datos etnohistóricos y según Maria Rostworowska, en el mundo precolombino andino la wiphala no era un elemento especialmente característico del imperio inca, a pesar de lo que hoy afirman muchos eruditos bolivianos, así como toda una nueva generación de líderes indígenas. Es cierto que sus motivos eran conocidos y estaban presentes en amplios sectores del imperio inca, pero aparecían junto a otros ornamentos y en una medida no particularmente intensa. Hoy, de un modo no totalmente auténtico, se buscan los orígenes de la wiphala, provocando con ello el debate y la controversia en amplias esferas sociales. A pesar de que esta bandera constituye, sin duda, un elemento reactivado de la rica tradición

Magdalena Śniadecka-Kotarska - ZSL Universidad de Lodz, CESLA Universidad de Varsovia. E-mail: m_kotarska@yahoo.com; m.sniadecka-kotarska@uw.edu.pl 
precolombina, el discurso actual acerca de su funcionamiento en torno al dinámico movimiento indígena que se desarrolla en todos los países andinos (Perú, Bolivia, Ecuador), así como los intentos de control sobre ella, merece un análisis más profundo. Tanto más por cuanto la insólita carrera de esta bandera como signo de la población indígena ilustra a la perfección un proceso más amplio: el de crear una memoria histórica propia y unificar étnicamente.

$\mathrm{Al}$ desarrollo del simbolismo multifuncional de esta bandera han contribuido diferentes gremios en diferentes esferas y momentos. En Bolivia, la wiphala apareció primero en un contexto político sobre los años 60 del pasado siglo. Fue ahí donde se hizo más fuerte y largo el discurso acerca de su significado cultural y simbólico, ante todo gracias a su primer historiador, el aymará Inka Wachapanki, que lleva escribiendo sobre ella desde hace 30 años con la intención de convencer de su origen precolombino. Fue también en Bolivia donde la wiphala se convirtió por vez primera en un emblema político: primero del partido India (1968) y después del MITKA y el MNTK; pero cabe subrayar que entonces era poco conocida, aparte de en un estrecho círculo de intelectuales aymará. Sin duda, en Bolivia esta bandera funciona hoy más ampliamente, lo que debe relacionarse con la llegada al poder del MAS y de Evo Morales (La Prensa 9.08.2001). Sin embargo, fue en Perú donde la bandera apareció por vez primera en un contexto folclórico como forma de reactivación de la tradición indígena local (años cuarenta del siglo veinte), lo que tal vez contribuyó a su posterior arraigo en Bolivia. Con todo, la prioridad y la tenacidad en el uso de esta bandera por parte de las masas populares, así como su introducción posterior en la vida política local y nacional, se debe sin duda a las organizaciones indígenas de Ecuador nacidas a caballo de lo siglos veinte y veintiuno.

\section{Terminología, formas y retórica de la wiphala}

La bandera utilizada en Perú y Bolivia se diferencia notablemente en forma, color y términos de la ecuatoriana. En Ecuador y Perú, es utilizada como bandera arco iris en forma rectangular con siete bandas horizontales con los colores del arco iris. Por el contrario, en Bolivia es más bien cuadrada con otros 49 cuadraditos con los colores del arco iris y con una banda claramente distinguible que sesga su fondo, además de con dos bandas simétricas a los lados con los colores del arco iris, que representa lo que hoy se conoce como fenómeno de fragmentación del arco iris. Esta diferencia de formas, nombres y colores es consecuencia de la propia diferencia en cuanto a la teoría de su origen. En Perú y Ecuador, el arco iris fue identificado con la hija del dios Illapa; por el contrario, en Bolivia su primera versión fue, según los eruditos, una representación de la fragmentación del arco iris. Este raro fenómeno meteorológico fue llamado en la época inca "kumisi" en quechua y "wiphala" en aymará, y en ambas formas fue considerado sagrado y adorado por los incas (Cardenas 2002). 
Según el Inka Chupiwanka, la wiphala abarca y refleja las estructuras más importantes y los principios organizativos de las sociedades precolombinas, es decir la unión de la comunidad y la relación del hombre con la naturaleza y el mundo, todo lo cual constituiría una cosmovisión específica: la importancia de la luna y el sol, la riqueza de la tierra y el agua, la claridad y la oscuridad, el movimiento y la inmovilidad, la uniformidad y la diferencia, la vida y la muerte, la vitalidad y la pasividad, la guerra y la paz, la masculinidad y la feminidad. Estas y otras complicadas teorías (no verificadas) del aymará Inka Chupiwanka han sido constantemente propagadas desde hace treinta años y han hecho de la bandera del arco iris un símbolo de la sociedad precolombina idealizada y discriminada a la par, hecho que se ha mantenido desconocido por sectores más amplios.

Cobró una nueva dimensión a medida que fueron tomando fuerza política los movimientos de protesta en los territorios andinos, lo que provocaría una auténtica furia entre los oponentes políticos, que no perdieron ocasión para ridiculizar el símbolo de los nuevos líderes políticos. Entre otras cosas llamaron a la wiphala "falso símbolo que prueba la pobreza de la tradición de sus creadores, es decir gente insignificante que desea existir gracias a la creación de nuevos mitos" (Quiroga 1993).

Es cierto que la mayoría de los artículos del Inka Chupiwanka se basan en premisas etimológicas poco sostenibles. En su opinión, la wiphala, por ejemplo, estriba en la unión de tres términos de la lengua winaymara (protoplasma del actual aymará): wi, que significa movimiento y difusión; pha o pa, que significa compartir y realizar la totalidad; la, que significa repetición, ciclos, continuidad. El autor se esfuerza por dar una imagen de verosimilitud, pero en realidad lo único que hace es reflejar sus lecturas de Lévi-Strauss. Él mismo tenía problemas con el término wiphala, pues en sus primeros artículos, del periodo 1980-1983, cambió varias veces la ortografía de la palabra: whipalla, wiphallla, por fin wiphala (Chupiwanka 1981-1983).

Según este mismo autor, los aymará y los incas, que adoraban el arco iris, tomaron su imagen como bandera para todo el imperio, lo que no encuentra ninguna corroboración científica, a excepción de ciertos datos en las Crónicas de Poma de Ayala, de algunos estampados en los tejidos y en las cerámicas de la época inca, todos de gran riqueza ornamental. Dejando aparte la imaginación de este y otros autores, lo que sí es cierto es que los orígenes de la wiphala se remontan al periodo precolombino, al que se le daría nueva interpretación a partir de finales del siglo veinte.

Soslayo aquí diferentes versiones acerca del simbolismo de sus colores, generalmente contradictorias, pues suelen basarse en trabajos referentes a otras cuestiones relacionadas con cada uno de estos países.

Con todo, algo no puede ser puesto en tela de juicio: la wiphala empezó a existir realmente en el contexto de los movimientos indígenas y se convirtió en el símbolo incuestionable de las protestas quechua y aymará, que exigieron a fines 
del siglo veinte cambios en su situación de marginación social, identificándose a la par con la cosmovisión precolombina, opuesta a la dominante blanco-mestiza de origen colonial. Las banderas utilizadas en las marchas, bloqueos, huelgas de la década de los 1990 desempeñaron un importante papel porque unieron a los manifestantes, crearon indirectamente y con el tiempo fortalecieron sus relaciones, edificaron un sentimiento de seguridad, unidad y solidaridad, sirviendo al mismo tiempo para recordar a los adversarios políticos la diferencia en cuanto a las expectativas de estos grandes grupos de ciudadanos, invisibles hasta entonces en la escena política.

\section{Historia de la bandera wiphala en Ecuador}

En Ecuador, el emblema del arco iris apareció a escala nacional en los movimientos indígenas en alza desde 1990 a 1992 organizados por la CONAIE. Una década más tarde, en agosto de 2001, la bandera aparecería ya en el primer encuentro histórico de las organizaciones indígenas con el presidente Nabot en Otavalo y, poco menos de un año después (enero de 2002), en las manifestaciones indígenas que llevaron a la caída de dicho presidente. Simbólicamente la bandera significaba la posición alcanzada por los indígenas en la escena política del país. La bandera del arco iris fue izada oficialmente en los edificios más importantes del país: Congreso de la República, palacio Presidencial y en la Plaza Grande de Quito. De este modo fue como el símbolo indígena, ignorado por los adversarios del cambio surgido en el año 1992, apareció por primera vez en el primer plano de la escena política de un país del continente americano. Al desarrollo del movimiento indígena se le unió esta bandera de forma inseparable, a pesar de que sus partidarios sufrieron persecución, cosa a menudo olvidada hoy en día. Cuando en 1992 se izó en la Iglesia de santo Domingo, fue secuestrada al cabo de unas horas y los indígenas que trataban de colgarla de nuevo fueron arrestados. En 1995 y 1997 fue colgada, por algunos días, en la Universidad Salesiana, y en 1997 durante unas semanas en el transcurso de las huelgas y protestas estudiantiles. Por este motivo, los profesores que apoyaban el movimiento fueron suspendidos temporalmente, retirados de sus cargos de responsabilidad o relegados a trabajos en diferentes regiones del país, como por ejemplo la selva. Desde 1996, la wiphala apareció única y dignamente en los edificios del Pachacutic, pero incluso ahí, en el año 2000, y a pesar de que alojaba a representantes indígenas elegidos democráticamente, fue ridiculizada por la vieja élite política y por ciudadanos de a pie, provocando en múltiples ocasiones destrozos en su emblema. Por ejemplo, en Otavalo, en cuyos cargos públicos se encontraban ciudadanos indígenas, la bandera fue izada y bajada en varias ocasiones del edificio Pachacutic. Cuando en ese mismo año se colgó en el ayuntamiento, dado que el alcalde era indígena, debía ser izada y bajada 
cada día para evitar actos de vandalismo, actos que provocaron indirectamente aversión en las recién iniciadas relaciones interétnicas. Además, el concentrarse en un asunto material como el de la bandera acabó por debilitarlas del todo. La noche del 21 de enero del año 2001, se pudo ver la wiphala en diversos puntos del país y esa misma noche el representante de CONAIE, Antonio Vargas, atravesó la Plaza Grande con la bandera, convirtiéndose así en toda una autoridad en el país.

En Ecuador, la bandera gozó de su mayor popularidad a principios del gobierno de Lucio Gutiérrez. Su alzamiento al poder, el entendimiento político y la participación indígena hicieron que la bandera del arco iris empezara a ser tratada como un emblema habitual en los edificios públicos del país: municipios, alcaldías, escuelas estatales e incluso en la sede de las organizaciones a favor de los indígenas. Esta situación cambió a raíz del conflicto entre los indígenas y Gutiérrez y de la crisis interna en el seno de las mismas organizaciones indígenas, de modo que su uso se limitó a los edificios del Pachacutic y a algunas escuelas bilingües. En los años siguientes, la bandera reflejaría la crisis de las organizaciones indígenas y apenas pudo vérsela en su mástil. Actualmente, desde el entendimiento y la llegada al poder del presidente Correa, empieza a ondear con mayor frecuencia en el fórum público y político, religioso y popular. Por ejemplo, durante el referéndum de septiembre de 2008 o durante el retorno a las fiestas religiosas de la Mama Negra en Lacatunga.

\section{Perú}

En las últimas dos décadas, los movimientos indígenas no se han desarrollado en Perú de un modo tan intenso a como lo han hecho en los países vecinos, debido al conflicto interno armado entre el gobierno y la guerrilla maoísta de Sendero Luminoso, en el que también tuvo intervención la población indígena de los Andes. Sin embargo, cuando surgió el movimiento en Cuzco en 1992, la wiphala se convirtió también en su emblema, tal vez siguiendo el ejemplo de los países vecinos. Con todo, cabe decir que esta bandera ya se había utilizado en la región de Cuzco con anterioridad, incluso antes que en Bolivia o Ecuador. Concretamente en 1944, en la celebración de la Fiesta del Sol, que después se llamaría Inti Raymi (De la Cadena 2004:152-197). Dicho fenómeno, que rememoraba la potencia imperial inca de Cuzco, influyó en los sectores eurocentristas e indígenas. Desde 1997, el emblema wiphala, un rectángulo con siete rayas horizontales, se convertiría en la bandera de esa ciudad, así como de la COPPIP (Coordinadora de los Pueblos Indígenas del Perú) y, desde 1998 también aparecería en las pancartas de la CONACAM (Coordinadora Nacional de Comunidades Afectadas por la Minería). Desde el año 2000, la wiphala fue utilizada, por una parte, en la campaña del candidato a la presidencia, Alejandro Torres, y por otra parte, por 
los adversarios del mismo. Paradójicamente, la wiphala estuvo presente tanto en la célebre marcha de Cuatro Suyu, que reunió a amplios sectores de la oposición política peruana, como en celebraciones folclóricas de propaganda, por ejemplo la organizada en las ruinas de Sacsahuaman, junto a Cuzco, para otorgar la ciudadanía a la esposa del presidente Alejandro Toledo. También se izó la bandera durante algún tiempo en el palacio presidencial de Lima junto a la bandera nacional, aunque no dejó de ondear en las protestas que tuvieron lugar durante las cadencias de Alejandro Toledo, entre otras en la organizada a raíz del asesinato del alcalde Ilave (departamento de Puno). Desde el 2005, la wiphala fue utilizada a su vez por los etnocaceristas, adversarios de Toledo, en las provincias de Apurimac, Ancasch y Puno. Al mismo tiempo, desde el 2002, vino a ser, a ejemplo de Bolivia, el emblema de la CONPACCP (Confederación de Productores Agropecuarios de las Cuencas Cocaleras del Perú de la Selva Alta), así como de otras muchas organizaciones opositoras al gobierno. En suma, el perfil social de las personas que se identifican con la wiphala en el Perú está lleno de contradicciones y es el menos claro si lo cotejamos con el de otros países.

\section{Bolivia}

Fue en Bolivia donde antes apareció la wiphala, pues se convirtió a fines de la década de los sesenta en el símbolo de los cataristas. Esta agrupación política, procedente de los primeros grupos de estudiantes aymará, retomó el tema de la etnicidad, ahogado oficialmente a raíz de las reformas de 1952, lo que provocaría un eficaz estallido de protestas, bloqueos y revueltas organizadas por las estructuras sindicales campesinas (Cárdenas 2002). Esta vuelta hacia el indigenismo, en un mundo dominado por una actitud clasista hacía los nativos, se había hecho ya patente no sólo en la recuperación de la memoria del legendario rebelde anticolonialista del siglo dieciocho Tupac Katari, sino también en la creación del Partido de la India de Bolivia. Los cataristas se concentraban, entre otras cosas, en la elaboración de su propio sistema de símbolos, por ejemplo la bandera wiphala. Podría decirse que fueron principalmente los intelectuales aymará quienes, al reactivar este elemento olvidado, al hacer de él paulatinamente un referente de la cosmovisión precolombina y al actualizarlo, convirtieron la wiphala en un símbolo político. Teóricamente, la bandera tenía que ser un signo de revalorización de las virtudes y las autoridades tradicionales que se referían a la llamada larga memoria histórica, en contraposición con la breve memoria histórica, concentrada tan sólo en los logros de la revolución de 1952. A los círculos cataristas pertenecen, entre otros, el Inka Chupiwanka, alias Germán Choque, y Constantino Lima. Ambos declaran ser los autores de la resurrección de la bandera wiphala. Resulta interesante, y desconocida, la versión de Constantino Lima, según la cual 
la reactivación de la bandera en Bolivia, a fines de los años 1960 del pasado siglo, sería debida a la influencia de los indígenas peruanos de los años 1940, cosa que ellos mismos ignorarían. En una entrevista concedida por Constantino Lima en el 2004, declaró:

copié en lápiz de un librito peruano, que a la sazón estaba leyendo, un ornamento. $E l$ indigenismo era en aquellos momentos un importante factor ideológico $y$, después, en 1975, este dibujo olvidado lo puse junto a mi casa como forma y reflejo del Movimiento Tupac Katari...y así se transformó en el símbolo del MITKA [Constantino 21.4.2004].

Del círculo catarista y del PIB nacieron otras dos organizaciones políticas indígenas: la más política MITKA (Movimiento Indio Tupac Katari), cuyo fundador real fue Constantino Lima, y el MRTK (Movimiento Revolucionario Tupac Katari), más de clase, que colaboraría y dominaría temporalmente la central sindical CSUTCB (Confederación Sindical Única de Trabajadores Campesinos de Bolivia), creada en 1979. Ambas organizaciones subrayarían por vez primera en 2000 años la presencia indígena de identidad campesina, y ambas, en determinadas esferas de su vida política, utilizarían la bandera wiphala. Constantino afirma que a la elección de esta bandera contribuyó la persecución de que eran víctimas los cataristas por aquella época:

La wiphala empezó a funcionar entre nosotros al precio de nuestra propia sangre. Por aquel entonces éramos atacados con saña en la universidad, tanto por la izquierda como por la derecha. Los primeros utilizaban la bandera roja, los segundos la gubernamental...nosotros debíamos tener nuestro propio símbolo...por eso sólo nosotros teníamos derecho a utilizarla. [Constantino 21.4.2004]

En 1980, de la CSUTCB surgió la primera organización campesina de mujeres indígenas, la Federación Nacional de Mujeres Campesinas Bartolina Sisa, conocida después como las bartolinas. En aquella época, la wiphala era conocida sólo en los estrechos círculos políticos de los intelectuales cataristas; más tarde sería adoptada y ampliamente difundida por las bartolinas. Tal vez porque se trataba de una organización no controlada por los intelectuales aymará, el uso de la bandera cobró una forma más auténtica y, al apoyarse únicamente en redes creadas sobre el terreno, pudo ser llevada de la ciudad al campo. Por eso, ahora, las bartolinas hacen hincapié con frecuencia en su mérito: el de haber sido las verdaderas difusoras de la wiphala y, en casos extremos, incluso minusvaloran el papel de los cataristas en dicha misión.

Sobre la adopción de esta bandera como un símbolo más amplio de los movimientos indígenas de mediados de los años 1980 también se pronuncia Pedro Portugal, ex catarista, en el boletín Chitakolla: 
En 1985 tuvimos en El Alto una larga serie de encuentros en los que se discutía sobre el emblema que debía adoptar nuestro movimiento. Como tenía que ser sobre todo un símbolo contra la ideología racista del Estado, tomamos la wiphala como un signo de nuestra propia opción política, y no la bandera roja como deseaban una parte de los nuestros, identificados a la sazón con la izquierda. La wiphala tenía que unirnos, aunque no sería así... [Robins 2002:11].

Generalmente, en la conciencia social de aquella época, esta bandera siguió siendo una desconocida, al contrario de lo que ocurría entre los intelectuales aymará, que sí fueron poniendo en marcha paso a paso su proceso de reactivación, lo cual se haría patente sólo al cabo de dos décadas. Precisamente, la historia de Germán Choque Condori es bastante típica e ilustra a la perfección cuán importante fue el papel de los cataristas en el proceso de reindigenización. Choque Condori, hijo de campesino andino, se sometió durante sus estudios en la Universidad de San Andrés a un proceso de "cholificación", es decir de conversión a la vida de un boliviano típico. Desde 1979, tras unirse a los cataristas (sobre todo debido a la opción de sus estudios), experimentó una profunda fascinación por la época inca y colonial. Su primer artículo trató justamente sobre la wiphala. Tanto fue su éxito, que los siguientes artículos también trataron sobre la cuestión indígena, lo cual le dio una gran fama, y no sólo entre los cataristas. Sus cambios internos se reflejaron también en cambios en su vida cotidiana, que se acercaría cada vez más a las formas de la tradición indígena precolombina. Primero cambió su apellido por el de Inka Kara Choquewanka (después Chuquewanka), se dejó melena y su atuendo y actitud se fueron asemejando a los de un indígena de la época colonial que tanto había estudiado.

Su carrera en el movimiento social, político y profesional fue consecuente: de ser miembro del Movimiento Julián Apaza (1977) y del Partido India (1978) pasó al MRTKA, para después militar en el Pachacutic y llegar hasta el Congreso y la Asamblea Constitucional con Evo Morales. Inka fue el primer diputado que se sentó en el Congreso (1977) con los cabellos largos atados con una pluma y ataviado con la camisa y el poncho campesinos. Actualmente lleva ya cuatro cadencias. Tras la guerra del gas se convirtió en miembro permanente de diferentes comisiones negociadoras. También desarrolló su carrera académica en la Universidad: primero fue profesor en la Universidad Mayor de San Andrés, después en la Universidad Nacional del Siglo XX y en el Instituto Normal Simón Bolívar, para terminar fundando la Universidad Indígena de Tawantinsuyu y la Universidad Pública de El Alto.

Los títulos de sus artículos y trabajos, así como los lugares de publicación, reflejan la importancia de su papel en la promoción y actualización de la wiphala como símbolo étnico: Wiphala, bandera india (1980), Wiphala comunitaria (1983), ¿Qué es la wiphala? (1989), Wiphalas comuneras y banderas coloniales en fiestas y conflictos (1993), Origen y constitución del carácter de la wiphala (2003), Wiphala 
guerrera (2005). Los dos primeros títulos fueron publicados por los cataristas, los otros por los sindicatos CSUTSUB y MP, los últimos por la editorial del Congreso. En estos trabajos sostiene la teoría de que la bandera del arco iris es un símbolo precolombino que mantuvo, durante la época colonial, los lazos de comunidad entre los indígenas, en sus fiestas, en sus conflictos internos, en el periodo republicano, hasta transformarse hoy en día en el emblema líder de los cambios revolucionarios habidos en las relaciones entre indígenas y Estado.

Sin embargo, cuando se le pregunta si ha sido el creador del emblema, lo niega terminantemente, aunque afirma (contrario a otras fuentes) que su creador es el pueblo indígena y que él mismo la recuerda haber visto siempre presente entre los indígenas andinos, bien en forma de rectángulo, bien de cuadrado, con 85 o con 90 cuadrados, con filas de cuatro, seis, siete o diez elementos. Reconoce a la par que los colores fueron ordenados por los miembros del MITKA mientras cosían las primeras banderas según los dibujos de Poma de Ayala, algo que tampoco corroboran las crónicas. Estos trabajos han sido realizados bajo la tutela del también catarista y profesor universitario Zenobio Ayala (Chuquiwanka 2003).

Los intelectuales aymará tuvieron sin duda fuerte influencia en la promoción de la imagen de la wiphala, incluso antes de ser popular entre los indígenas, gracias también a algunas películas bolivianas. La wiphala apareció, entre en otras, en la película de Jorge Sanjínez La nación clandestina (1989), de gran acogida internacional. Tras la recogida de premios, las declaraciones del director - en las que afirmaba que la bandera simboliza la tradición del mundo indígena y negaba los gobiernos de la élite blanca- no fueron comprendidas ni por los espectadores extranjeros, ni por los bolivianos de la época.

La bandera siguió siendo una desconocida en la escena social y política de Bolivia, aunque el primer diputado aymará del Congreso, el conocido catarista Hugo Cárdenas, que después sería vicepresidente por el MRTK (1991-1994), no dejaba de recordarla.

En Bolivia, la wiphala empezó su extraordinaria carrera y desarrollo con las crecientes protestas de los años 1990, con la actuación del partido MAS y la subida al poder de Evo Morales. La wiphala se convirtió en el símbolo incuestionable de los movimientos indígenas del siglo veinte-veintiuno y, durante las campañas electorales del 2002-2006, en el del MAS, lo cual tropezó y tropieza con la crítica de diversos grupos, no sólo de oposición política, como por ejemplo la de los ex cataristas del Mallku Quispe, que lo consideran una apropiación indebida por parte de ese partido. Por otro lado, el partido de oposición PODEMOS reprocha a los políticos indígenas el difundir la wiphala en detrimento de la bandera nacional de Bolivia. Otros opositores, deseosos de herir el orgullo indígena, afirman que el símbolo del arco iris es también propio de otras culturas: desde la Biblia hasta las banderas de Carlos I, pasando por grupos contestatarios actuales (Díez de Molina 
2007:11). Los cierto es que, en 1958, con motivo de la concesión del Premio Nobel a Bertrand Russell, el arco iris de Gerald Holtom se convirtió en el símbolo de los grupos antinucleares; en 1961, el dibujo de Picasso de una paloma sobre el fondo del arco iris se consideró símbolo internacional de la paz; en 1978, su imagen pintada por Gilbert Baker es el símbolo actual del movimiento gay desde sus inicios en San Francisco. Actualmente, no sólo en Bolivia, también en el seno del MAS, la wiphala despierta cada vez más emociones y discusiones. El MAS es un partido muy dividido en su interior. Se compone de varios grupos unidos muy laxamente y de diversa procedencia. A sus líderes, antes procubanos y ahora prochavezistas, se les reprocha aprovechar la wiphala para lanzar ideas de socialismo indígena, lo que está en desacuerdo con otras ramas del MAS. Por ejemplo, hubo protestas en el año 2007, con ocasión de la erección del monumento a Che Guevara en El Alto, donde esta bandera se utiliza con más profusión.

Es un hecho incuestionable que la wiphala, desde el 2006, es omnipresente: en el interior y en el exterior de los edificios públicos, en los gabinetes y escuelas, en las iglesias de cualquier confesión, en las oficinas, en los medios de comunicación, en la mayoría de tiendas y restaurantes, en las cantinas populares e incluso en las discotecas (por ejemplo, en Chaca Uma, en la calle Illampu de La Paz). Esta situación despierta la sospecha de que no todos aquellos que exponen este emblema lo hacen de modo auténtico, por convicción, más bien parece una cuestión coyuntural. Asimismo, en Bolivia la wiphala se halla presente en la mayoría de las fiestas nacionales, religiosas, manifestaciones culturales, reuniones de diferentes estamentos e incluso conferencias. Paralelamente, desde hace algunos años funciona como elemento de la imaginería artesanal, tanto de la auténtica como de la comercial. Se vende en todas partes: calles, aeropuertos, desde banderas a llaveros. Cerámica, textil y joyería llevan su imagen, para fines turísticos extranjeros y nacionales. También aparece tanto en los "chulos" - las fajas y bufandas de los líderes indígenas- como en los trajes elegantes producidos para la exportación. Ejemplo todo de su extraordinario éxito y gran promoción.

En Internet, la publicidad de la wiphala aumenta de día en día, sobre todo en su versión de calendario cósmico aymará (lo que despierta las protestas de los quechua), con simbolismo esotérico y específico código ético. La promoción de la bandera se desarrolla, por tanto, fuera de las auténticas vías indígenas. Desde 2005, las fotografías de los indígenas con la wiphala se han convertido en el motivo preferido para la ilustración editorial nacional y extranjera referente a Bolivia.

\section{Conclusiones}

Las banderas wiphala de diferente tamaño, incluso sólo como emblema, se han convertido en un símbolo inseparable y elemento de los movimientos de 
protesta, las organizaciones y los partidos indígenas desde los años 1990 hasta las primeras décadas del siglo veintiuno, así como de su infraestructura propagandística. La bandera es, sin duda, más un elemento fabricado por los intelectuales indígenas que reactivado, pero su masiva utilización por los movimientos de protesta lo han popularizado a una escala inusitada en una gran brevedad de tiempo. Han sido precisamente los indígenas quienes le han dado un sello irrepetible y una significación importante, que responde a la actual coyuntura histórica y a los procesos de cambio sociopolítico. La bandera se ha convertido en poco tiempo en el símbolo incuestionable de los países andinos de principios del siglo veintiuno. El último ejemplo, que demuestra la carrera relámpago de la wiphala, lo constituye el hecho de haber sido introducida en fin del año 2010 en los uniformes de la policía y el ejército bolivianos, junto a la bandera nacional, aunque sólo en los departamentos serranos, lo cual viene a corroborar las fracturas internas en el curso de los cuatro gobiernos de Evo Morales y su proceso de descolonización.

El juego de símbolos es el rasgo decisivo de la mayoría de los movimientos y organizaciones en el mundo. La insólita carrera de la wiphala indica cuán rápido ha sido el proceso de mitificación de este símbolo, cuán importante ha sido su papel auxiliar en los procesos de unificación, reconocimiento y reconstrucción de la identidad indígena, de la elaboración de su conciencia social de las regiones andinas entre los siglos veinte y veintiuno.

Traducido al español por Pilar Gil de Canova

\section{Referencias bibliográficas}

Albo, Xavier

2008 Movimientos y poder indígena en Bolivia, Ecuador y Perú. CIPCA, La Paz.

Cárdenas, Víctor Hugo

2002 Wiphala símbolo de interculturidad, La Razón 11 de noviembre. La Paz. Diez de Medina, José

2007 La wiphala, La Prensa 17 de febrero. La Paz.

Chiriboga, Manuel

2001 El levantamiento indígena ecuatoriano de 2001; interpretación. Iconos 10:28-33. Quito.

Chukiwanka, Inka Waskar

1981 Wiphalla bandera India. Colección de Folletos para la formación indianista 3:156. La Paz.

1983 Whipalla comunitaria. Encuentro de Estudios Bolivianos 5:3. La Paz.

1989 Qué es la wiphala. CSUTSUB, Potosí. 
2001 El origen de la actual wiphala. La voz del Condor 6:1-3. La Paz.

2003 Origen y constitución de la wipala. La Paz.

Guerrero, Andrés

2000 El proceso de identificación: sentido común ciudadano, ventriología y transescritura. Flasco, Quito.

Guzmán, Augusto

2001 Mallku con wiphala y Kollasuyu contra las FFAA. La Prensa 9 de agosto. La Paz. Lima, Constantino

2004 Entrevista. La Prensa 21 de abril: C7. La Paz.

Pacari, Nina

2005 La experiencia del Ecuador (1997-1998). Debate Político 14:47-96. ILDIS, Quito -La Paz.

Pajuelo Tevez, Ramón

2007 Reinventando comunidades imaginadas. Movimientos indígenas, nación y procesos sociopolíticos en los países centroandinos. IFEA y IEP, Lima.

Quiroga, Gonzalo

1993 La wipala y su falso símbolo. Ultima hora 27 de junio: B6. La Paz.

Robins, Maria

2002 Mallku insiste en suplir la tricolor de bandera con la Wiphala. Correo del Sur 20 de octubre.

Soria, Óscar

2007 El cine boliviano 10. La Paz. Universidad Politécnica Salesiana

2002 El grito de Arco Iris. Abya-Yala, Quito.

Zamosc, Leon y Nancy Postero (editores)

2005 La lucha por los derechos indígenas en América Latina. Abya-Yala, Quito. 


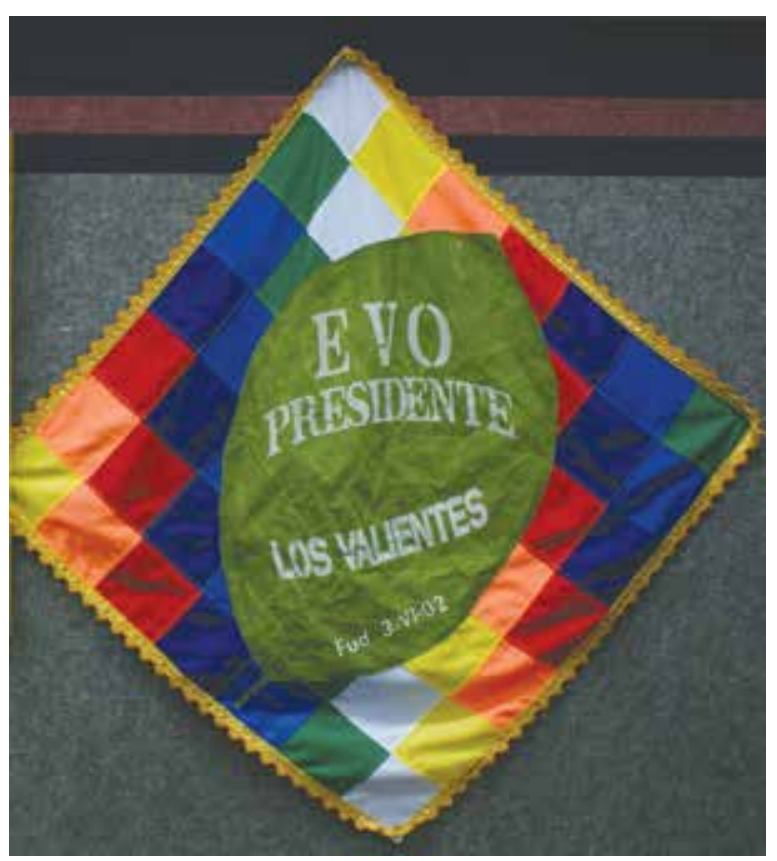

Figura 1. La inscripción propagandística de Evo Morales en la Wiphalla, Septiembre del 2002 (Foto: M. Śniadecka-Kotarska).



Figura 2. Las manifestaciones indigenas en Plaza Murillo en La Paz, Octubre del 2005 (Foto: M. Śniadecka-Kotarska). 


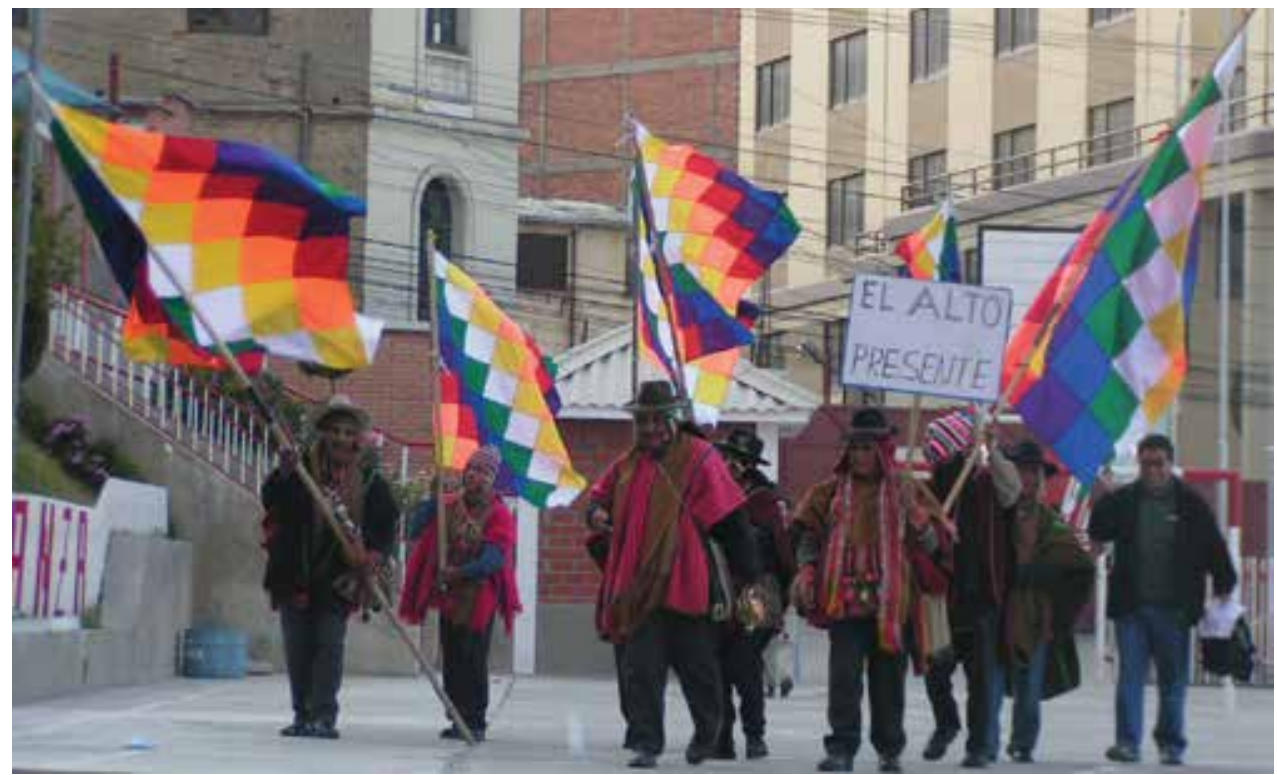

Figura 3. La delegacion de El Alto, viniendo al I Encuentro Intercontinental de Nacionalidades y Pueblos Indigenas en La Paz, Septiembre del 2006 (Foto: M. Śniadecka-Kotarska).

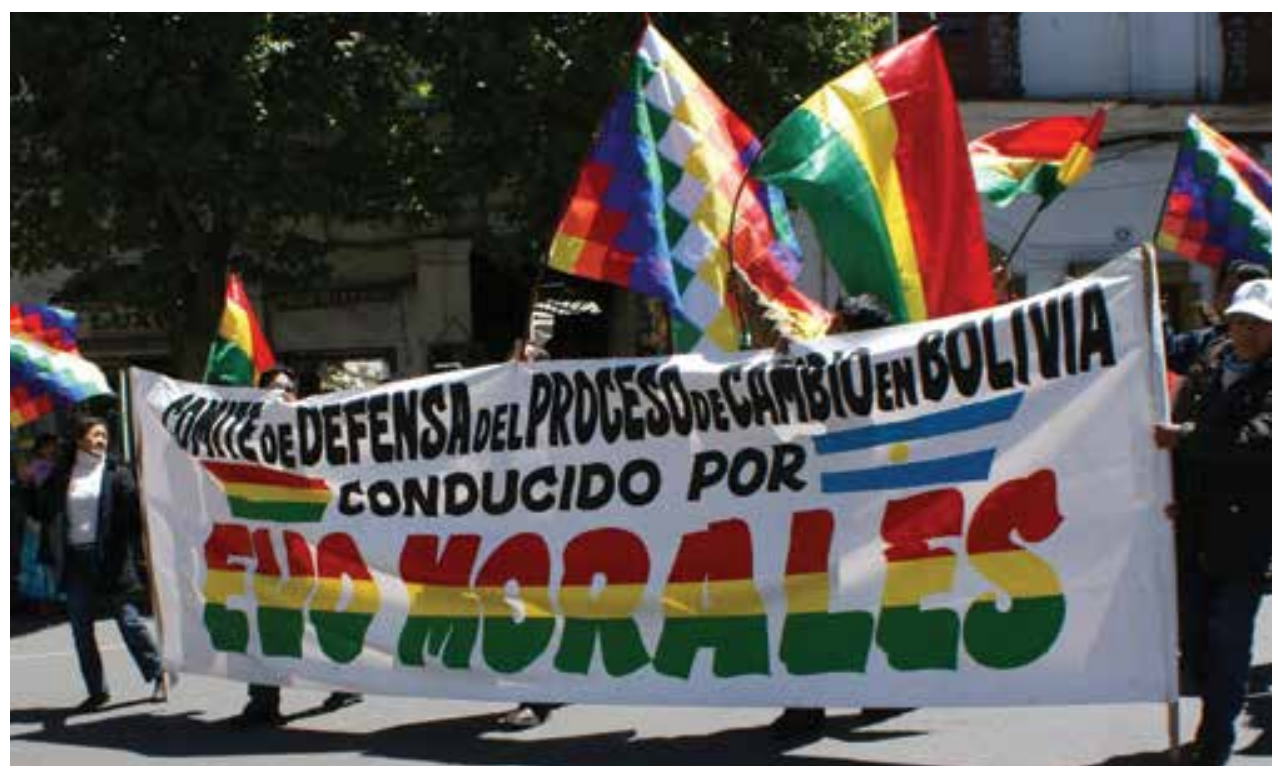

Figura 4. Las marchas del apoyo para las reformas introducidas por de Evo Morales, Septiembre del 2007 (Foto: M. Śniadecka-Kotarska). 


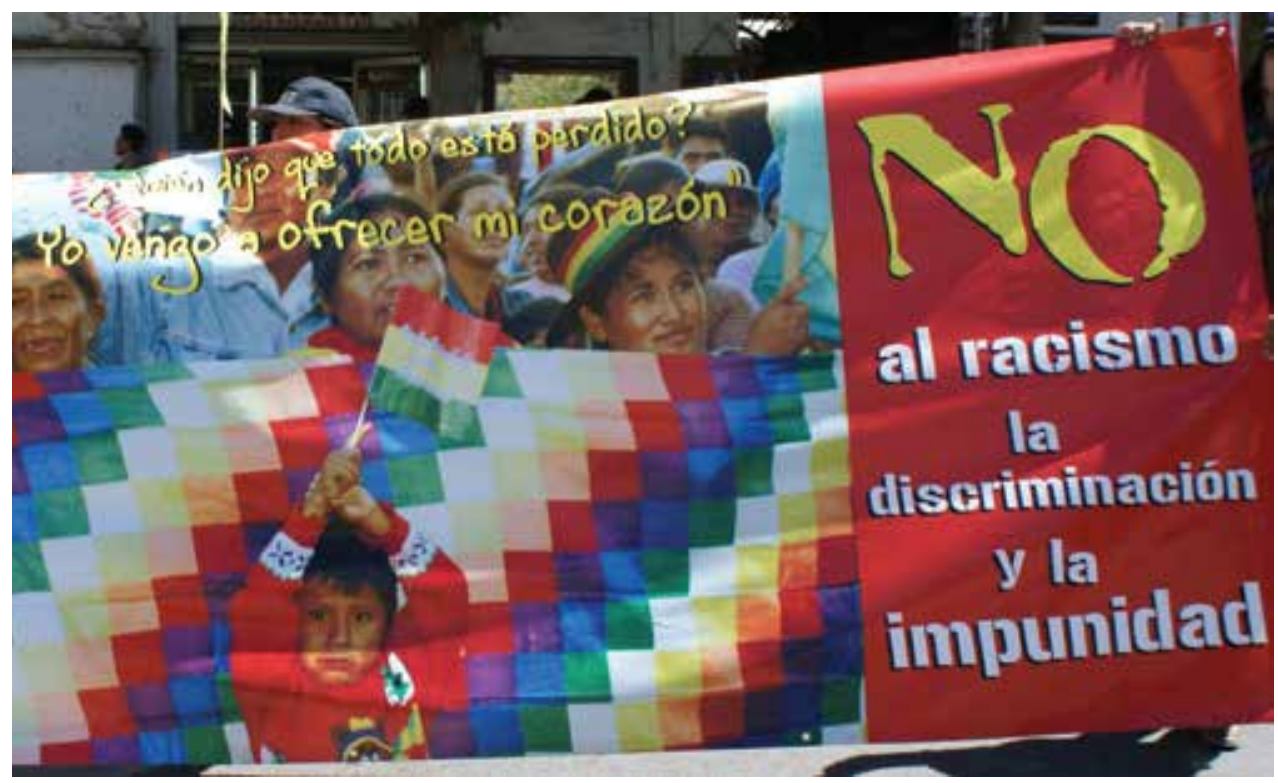

Figura 5. Las marchas del apoyo para las reformas introducidas por de Evo Morales, Septiembre del 2007 (Foto: M. Śniadecka-Kotarska).

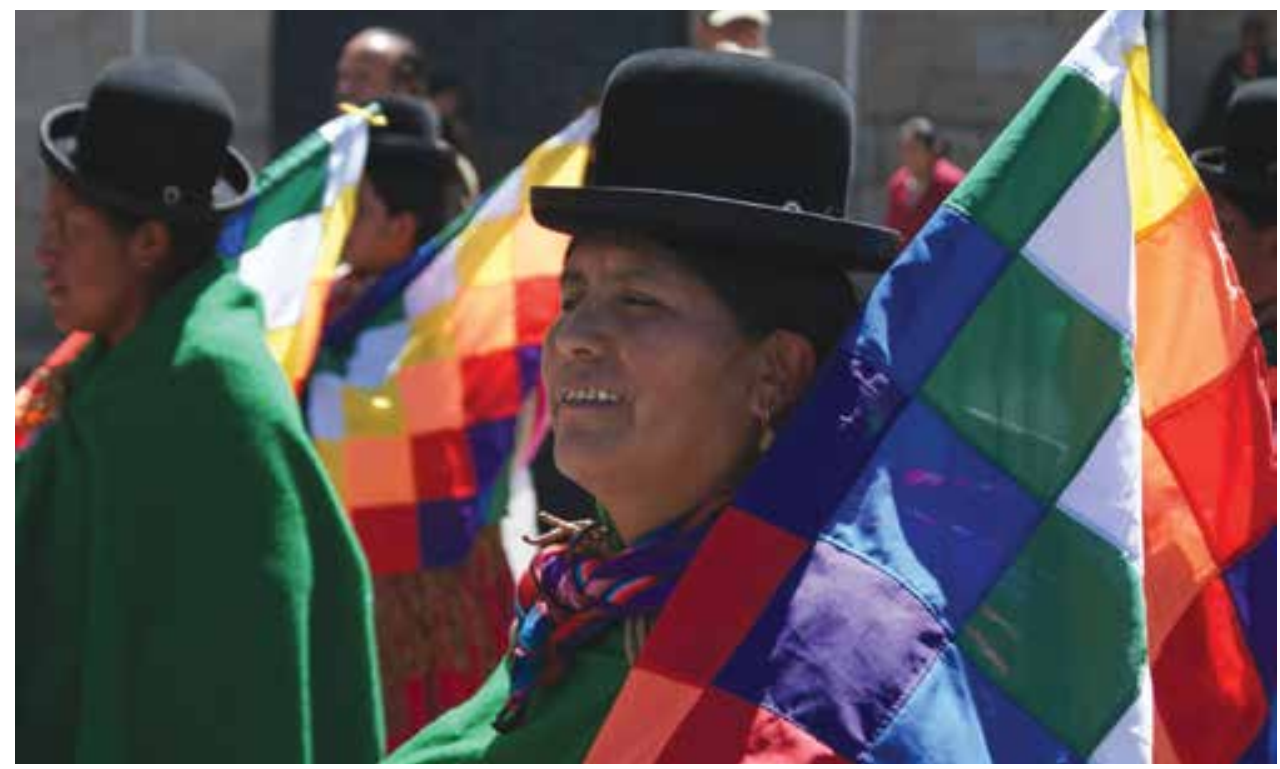

Figura 6. El dia de la Mujer Indigena, Octubre del 2008 (Foto: M. Śniadecka-Kotarska). 




Figura 7. Los lideres Indigenas durante la fiesta Madre Pacena, Septiembre del 2009 (Foto: M. Śniadecka-Kotarska). 


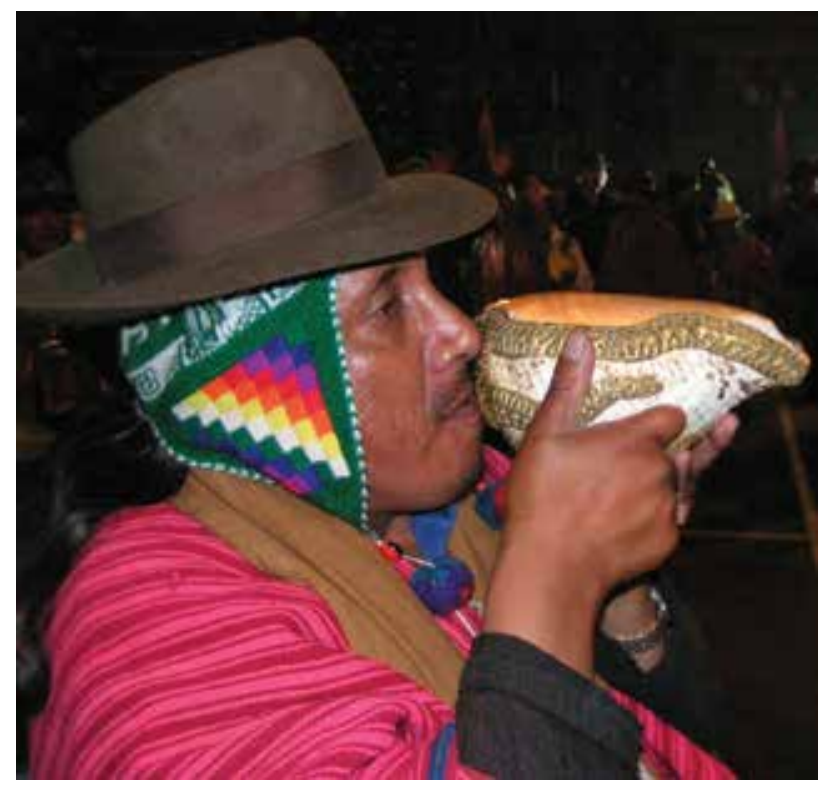

Figura 8. Los lideres Indigenas durante la fiesta Madre Pacena, Septiembre del 2009 (Foto: M. Śniadecka-Kotarska).



Figura 9. El policia con pegatinas de doble banderas en su uniforme, Septiembre del 2010 (Foto: M. Śniadecka-Kotarska). 